\title{
DEVELOPMENT AT THE AGE OF 2 AND 3 IN RELATION TO COGNITIVE ABILITIES AT THE AGE OF 5 IN VERY PRETERM CHILDREN
}

E. Potharst ${ }^{1,2}$, B. Houtzager ${ }^{1}$, L. van Sonderen ${ }^{3}$, P. Tamminga ${ }^{3}$, J. Kok ${ }^{3}$, B. Last ${ }^{2,4}$, A. van Wassenaer ${ }^{3}$

${ }^{I}$ Neonatology and Psychosocial Department, Emma Children's Hospital, Academic Medical Centre,

${ }^{2}$ Developmental Psychology, EMGO Institute for Health and Care Research of the Free University,

${ }^{3}$ Neonatology, ${ }^{4}$ Psychosocial Department, Emma Children's Hospital, Academic Medical Centre, Amsterdam, The Netherlands

Aims: This study investigates agreement between mental development at age 2 and 3 and cognitive development at age 5 in very preterm children, and the prediction of separate cognitive abilities at age 5 by development at toddler age.

Methods: Preterm born children ( $\mathrm{n}=102, \mathrm{GA}<30$ weeks and/or $\mathrm{BW}<1000$ grams) were assessed at age 2 and 3 using BSID-II, CBCL and Hempel neurological examination, and at age 5 using WPPSI-III (full scale, verbal and performance intelligence, processing speed).

Results: Agreement between mental development at age 2 and cognitive development at age 5 was substantial $(\kappa=0.48)$ and between age 3 and age 5 moderate $(\kappa=0.40)$. Mental development at age 2 and 3 explained half the variance of full scale and verbal intelligence. Performance intelligence and processing speed were less strongly associated with early mental development. Other areas of development at age 2 and 3 related to 5-year cognitive functioning when mental development was already accounted for, were behavior (full scale intelligence) and psychomotor and neurological functioning (processing speed). Perinatal en sociodemographic characteristics were associated with 5 year cognitive outcome as well.

Conclusions: Agreement between mental development at toddler age and cognitive development at age 5 is moderate to substantial. The prediction of full scale and verbal intelligence is reasonable, but performance and information processing abilities are more difficult to predict by early developmental assessment. Followup until at least age five is needed to be able to distinguish between different aspects of cognitive development, and reveal specific learning deficits. 